\title{
Modeling and Simulation with Experimental Validation of Temperature Distribution during Solidification Process in Sand Casting
}

\author{
C M Choudhari \\ Research Scholar \\ Department of Production \\ Engineering V.J.T.I., Mumbai, \\ India
}

\author{
B E Narkhede \\ Professor, \\ Department of Production \\ Engineering V.J.T.I., Mumbai, \\ India
}

\author{
S K Mahajan \\ Director, \\ Technical Education, \\ Maharashtra State, Mumbai, \\ India
}

\begin{abstract}
The solidification of metals continues to be a phenomenon of great interest to physicists, metallurgists, casting engineers and software developers. It is a non-linear transient phenomenon, posing a challenge in terms of modelling and analysis. During the solidification of a casting in a mould, the heat-transfer between the casting and the mould plays a vital role. This paper attempts to study heat flow within the casting, as well as from the casting to the mould, and finally obtains the temperature history of all points inside the casting. The most important instant of time is when the hottest region inside the casting is solidifying. ANSYS software has been used to obtain the temperature distribution in the casting process by performing Transient Thermal Analysis. Results obtained by simulation software are compared with the experimental reading of temperature and found to be in good agreement. Further the significance of filling pattern and appropriate orientation of gating system has also been studied. Thus, it was observed that the simulation of casting helps in obtaining temperature distribution of various parts of the mould which is an important factor in improving the casting quality. It also helps in reducing the cost of development and material utilization (yield)
\end{abstract}

\section{Keywords}

Casting, Solidification, Thermal, Simulation, Temperature Distribution

\section{INTRODUCTION}

Metal casting is one of the direct methods of manufacturing the desired geometry of component. Casting rejections are of a major concern in the foundry industry. Great saving of materials, energy and time can be achieved, if casting design can be corrected prior to moulding on the basis of defects prediction $[1,2]$. These facts make solidification simulation, a powerful tool to help the foundrymen in predicting casting defects. To identify the process parameters and their optimum values, simulation of solidification process is done by running indigenously developed computer software for the casting process selected for investigation. The program output provides the details of time-temperature profile which plays a key role in the effective design of castings [3].

\section{LITERATURE REVIEW}

From the existing literature it is also found that numerical methods for solidification simulation have received considerable attention from researchers in the past. The casting shape is broken down into a number of simple elements and the unsteady-state heat conduction equation is applied to them over a number of time steps in order to obtain the temperatures at different nodes. To do this, finite difference (FDM), finite element (FEM) and, recently, boundary element (BEM) methods have been used [4]. Heatflow through the sand mould was studied by many researchers and their achievement and limitations are discussed here. Seetharamu et al. [5] studied the solidification phenomena in sand mould for thermal stress using FEA and they discussed about the effect of solidification on stress formation in casting where the experimental data was available. Pequet et al. [6] studied the defects formation during solidification of $\mathrm{Al}$ alloy using ABAQUS and showed that most of the defects formed where the metal solidified last. Mirbagheri et al. [7] has studied the melt flow and effect of mould roughness of sand mould. Computational results were verified by casting of an aluminum alloy within a transparent mould and the mould erosion at different times has been recorded. Kulkarni and Radhakrishna [8] studied the solidification time of a hollow cylindrical shape casting in sand mould using ANSYS as a FEA package. Kermanpur et al. [9] studied the melt flow and solidification in the multi-cavity mould for automotive components made of gray cast iron. The process model developed was used to investigate the appropriateness of the running and feeding systems. Masoumi et al. [10] studied the effect of gating design on mould filling for light metal casting processes. The experimental results showed that the geometry and size of the gate and the ratio of the gating system has a great influence on the pattern of mould filling. Hassan Iqbal et al. [11] investigated the impeller shaped casting using MAGMASOFT Software. The effect of the location and size of risers and gates on parameters such as filling pattern, pressure and velocity, cooling rate, solidification and related defects were studied. The predicted results were then compared with experimental data, and an excellent agreement between them was reported.

Based on literature survey it was identified that solidification analysis has been attempted by various techniques such as analytical or numerical, based on software or by performing experimental trials. Researchers have used one of these techniques or a combination of them. Also, that very less work has been done for a long cylindrical shape casting having H/D >10 (H-height of cylinder and D-diameter of cylinder). Here an attempt is being made to perform solidification analysis in cylindrical sand casting by using finite element simulation with experimental validation.

The most important instant of time is when the hottest region inside the casting is solidifying, which helps in identifying the hot spot. This requires an analysis of heat flow within the casting, as well as from the casting to the mould, and finally the temperature history of all points inside the casting. 
This paper proposes a systematic procedure to obtain the temperature history of all points inside the casting, plot the progress of solidification fronts (isothermal contours) at different instants of time, and identify the last freezing regions. This immensely helps in identifying the appropriate location of the riser.

\section{MATHEMATICAL ANALYSIS}

When the molten metal is poured into the mould cavity, it releases large amounts of heat in a very short period of time, raising the temperature of the mould in a flash. At the same time, the mould absorbs the heat through conduction, convection and radiation. After a period of time, the temperature of the mould achieves a relative balance point. When the cavity is completely filled with the liquid metal, the solidification process is basically seen as an unstable process of heat conduction. [12].

According to the characteristics of casting, the two dimensional unsteady temperature field is adopted, as mentioned in equation 1 .

$\frac{1}{r}\left(\frac{\partial}{\partial r}\left(k \cdot r \frac{\partial T}{\partial r}\right)\right)+\frac{1}{r^{2}} \frac{\partial}{\partial x}\left(\frac{\partial T}{\partial \varphi}\right)=\rho \cdot c \cdot \frac{\partial T}{\partial t}$

where $\mathrm{r}, \varphi$ are the cylindrical coordinates in Fig. 1. $\rho$ Density, $\mathrm{c}$ - Specific heat, $\mathrm{t}$ - Time, $\mathrm{T}$ - Temperature, $\mathrm{k}$ Thermal conductivity. This is a case of transient heat transfer analysis of a casting process [13].

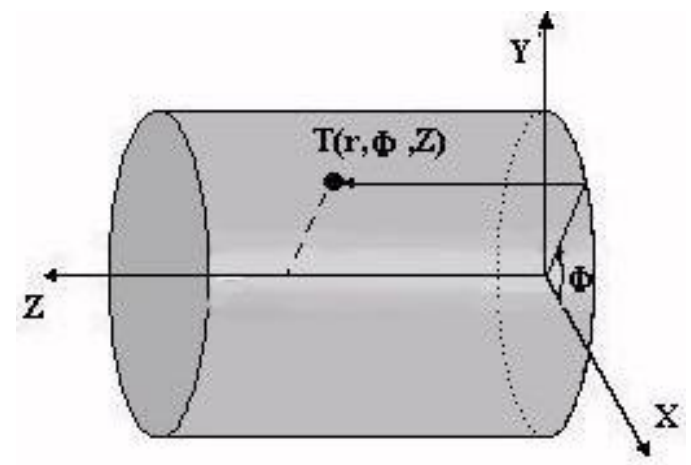

Fig. 1 Cylindrical co-ordinate system

The objective is to track the temperature distribution in the cylindrical shaped aluminium casting during the solidification process, over the duration of 60 minutes. The casting is made in a sand mould with $41 \mathrm{~mm}$ diameter and $413 \mathrm{~mm}$ length. Fig 2 shows the solid model of the cylindrical sand casting. ANSYS 12.0 has been used for modeling and simulation for the above case study.
5

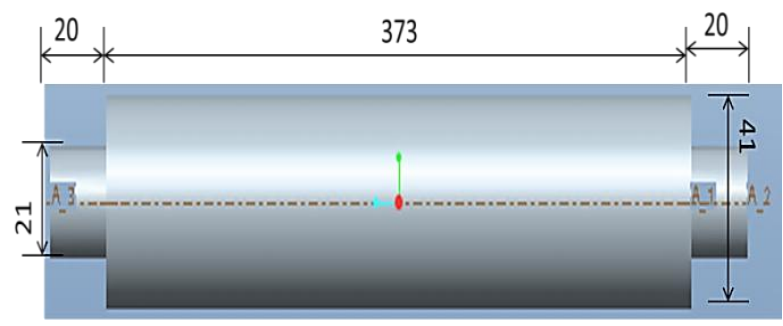

All dimensions are in $\mathrm{mm}$

Fig. 2 Solid Model of the casting

\section{PROCEDURE FOR THERMAL ANALYSIS USING ANSYS $[14,15]$}

\subsection{Pre processing Step 1: Model generation}

Axisymmetric shape of cylindrical casting has been assumed. This can be idealized as the 2-D analysis of a slice with unit thickness. Half symmetry is used to reduce the size of the model. In this study the left half portion is decided to be modeled into ANSYS environment as shown in Fig. 3.

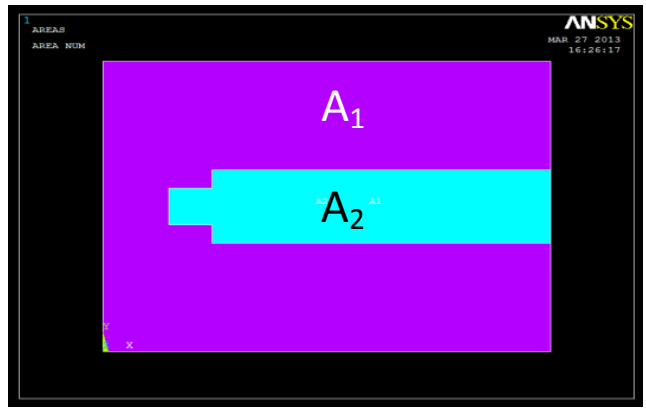

Fig. 3 Area plot of the model in Ansys (A1: Mould area, A2: Casting area)

\section{Step 2: Define material properties}

Two materials have been considered, one of the mould (A1) and the other of the casting (A2) as sand and aluminium, respectively. Sand has constant properties irrespective of the temperature; therefore properties demanded by the software for sand are as follows (Material no.1 Refer Table1):

Table 1 Material Property of Sand [16]

\begin{tabular}{|l|l|}
\hline Conductivity $(\mathrm{k})$ & $0.519 \mathrm{~W} / \mathrm{m} \mathrm{K}$ \\
\hline Density $(\rho)$ & $1495 \mathrm{Kg} / \mathrm{m}^{3}$ \\
\hline Specific heat $(\mathrm{c})$ & $1172.304 \mathrm{~J} / \mathrm{Kg} \mathrm{K}$ \\
\hline
\end{tabular}

Density and specific heat of Aluminium for this simulation have been considered as $2650 \mathrm{~kg} / \mathrm{m}^{3}$ and $921 \mathrm{~J} / \mathrm{kg}$, respectively. Other properties such as conductivity and enthalpy change with temperature. This change occurs as enthalpy content of aluminium changes.

Therefore properties demanded by the software for Aluminium are as follows (Material no.2 Refer Table 2): 
Table 2 Property of Aluminium [16]

\begin{tabular}{|c|c|}
\hline \multicolumn{2}{|c|}{ Conductivity (k) for Aluminium (W/m K) } \\
\hline At $293 \mathrm{~K}$ & 240 \\
\hline At $523 \mathrm{~K}$ & 230 \\
\hline At $831 \mathrm{~K}$ & 100 \\
\hline At $973 \mathrm{~K}$ & $7.8886 \mathrm{E}-031$ \\
\hline \multicolumn{2}{|c|}{ Enthalpy (H) for Aluminium $\left(\mathrm{J} / \mathrm{m}^{3}\right)$} \\
\hline At $293 \mathrm{~K}$ & $6.2967 \mathrm{E}+008$ \\
\hline At $523 \mathrm{~K}$ & $1.7961 \mathrm{E}+009$ \\
\hline At $831 \mathrm{~K}$ & $2.1527 \mathrm{E}+009$ \\
\hline At $973 \mathrm{~K}$ & \\
\hline
\end{tabular}

Step 4: Defining the element and mesh Generation

Thermal Solid - PLANE35 is used as a plane element with a 2-D thermal conduction capability. Fig. 5 shows mesh view of the model.

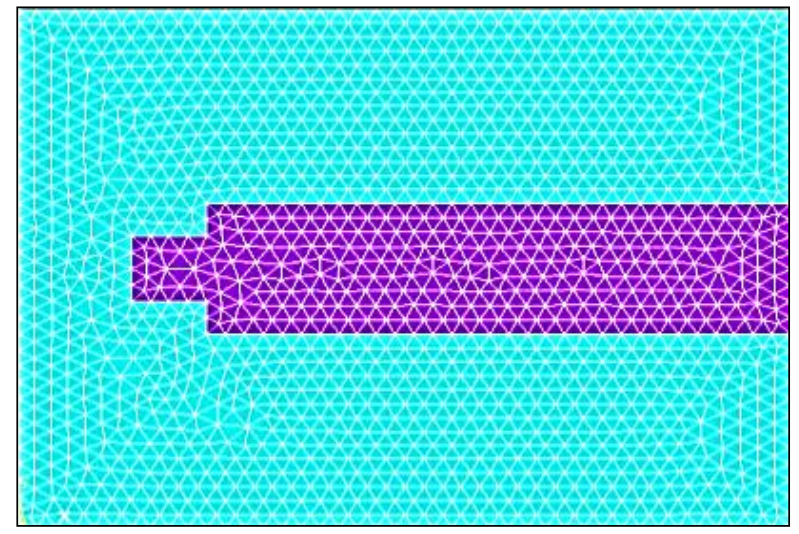

Fig. 5 Mesh view

Total 3556 triangular element has been used to discretize the model. It has generated total 7346 number of nodes. Out of which 1263 number of nodes belong to casting region and 6083 number of nodes belong to mould region.

Step 5: Apply convective load and boundary conditions for analysis

Convective Load was applied to the lines of the model exposed to the ambient air as shown in Fig. 6. Loads applied to solid modelling entities are automatically transferred to the finite element model during solution.

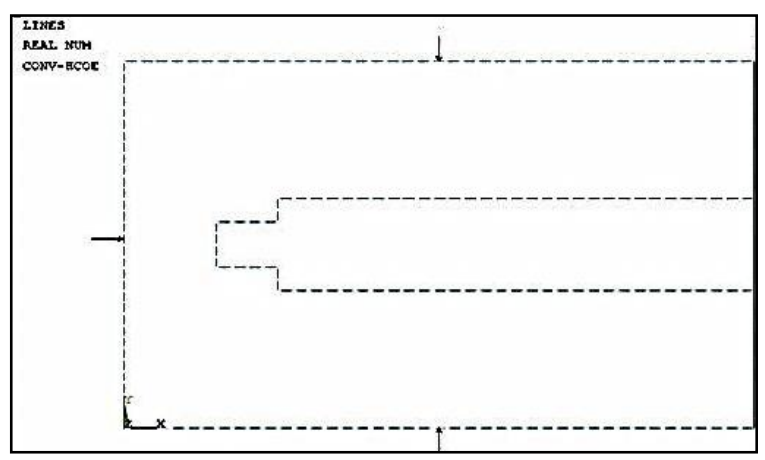

Fig. 6 Application of convective load
Here, heat transfer coefficient between sand and air has been considered as $10 \mathrm{~W} / \mathrm{m}^{2} \mathrm{~K}$ and ambient air temperature as 303 $\mathrm{K}$. The mould is initially at an ambient temperature of $303 \mathrm{~K}$ and the molten metal is at $973 \mathrm{~K}$.

\section{Step 7: Obtain Solution}

Here Define Analysis Type as Transient thermal analysis for Solution method as Full.

\section{Step 8: Set time, time step size and related parameters}

Stepped boundary conditions simulate the sudden contact of molten metal at $973 \mathrm{~K}$ with the mould at ambient temperature. The program will choose automatic time stepping that will enable the time step size to be modified depending on the severity of nonlinearities in the system (for example, it will take smaller time steps while going through the phase change). The maximum and minimum time step sizes are selected as $900 \mathrm{sec}$ and $3.6 \mathrm{sec}$ respectively.

\subsection{Processing}

This is second phase of finite element analysis carried out with the help of ANSYS software. In this step, the simulation is carried out. While ANSYS is solving the analysis, the Graphical Solution Tracking monitor plots the Absolute Convergence Norm as a function of the Cumulative Iteration Number. Here it is expected that the solution is assumed to have converged for values less than or equal to the convergence criteria.

The HEATCRIT curve refers to the convergence criteria heat value, which is equal 0.001 (VALUE) $\mathrm{x} \quad 0.5 \%$ (TOLERANCE). The HEAT L2 curve refers to the L2 Vector Norm of heat. For each substep, ANSYS iterates until the HEAT L2 value is below the HEATCRIT value. Once this occurs, it is deemed that the solution is within tolerance of the correct solution and it moves on to the next substep. The graph of Absolute Convergence Norm v/s Cumulative Iteration Number for the simulation under consideration is shown in Fig. 7.

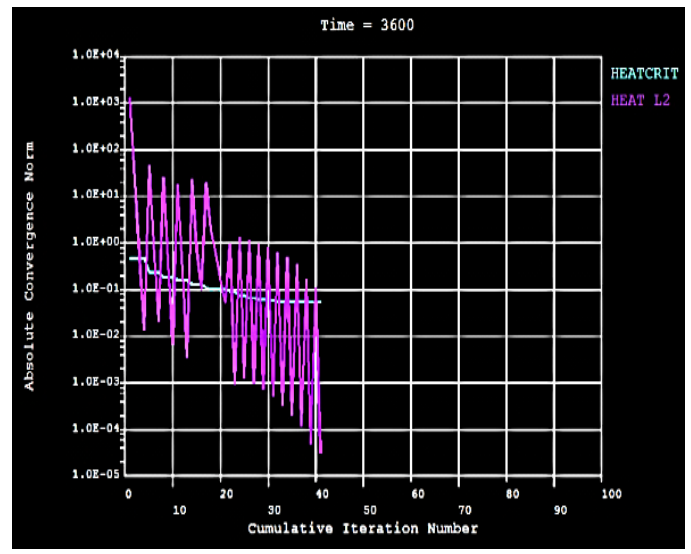

Fig. 7 Convergence Plot

\subsection{Post processing}

Temperature variation of any node in mould area can be found out with time-history post processing. Temperatures for specific nodes based on thermocouple's location are mentioned in result.

\subsubsection{Temperature plots}

The results were obtained for one hour duration. Fig. 8 (a-d) shows the temperature variation captured at eight different 
time instances i.e. 36, 1054, 2582, 3600 seconds. Fig 8 (d) shows the contour plot at the last time step with the hot spot at the central region of the cylindrical shaped casting, which is expected as this zone will solidify at the end.
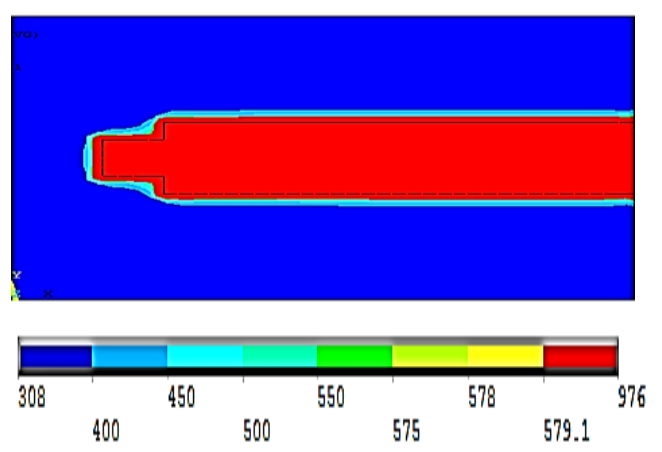

Fig. 8 (a) $t=36$ sec, $T \max =878.901 \mathrm{~K}$

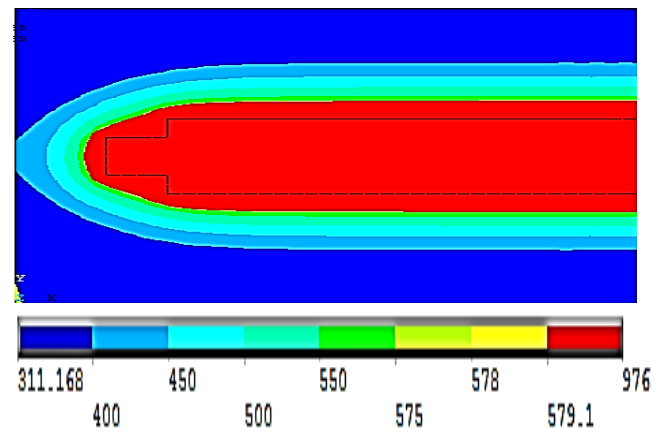

Fig. 8 (b) $t=1054$ sec, $\operatorname{Tmax}=684.365 \mathrm{~K}$

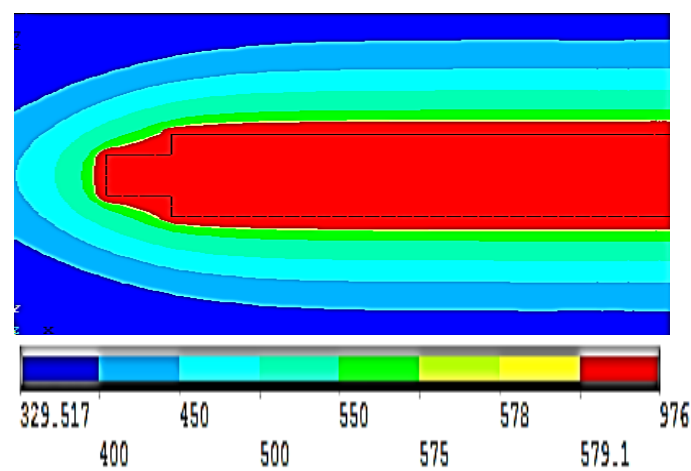

Fig. 8 (c) $t=2582 \mathrm{sec}, \mathrm{Tmax}=609.312 \mathrm{~K}$

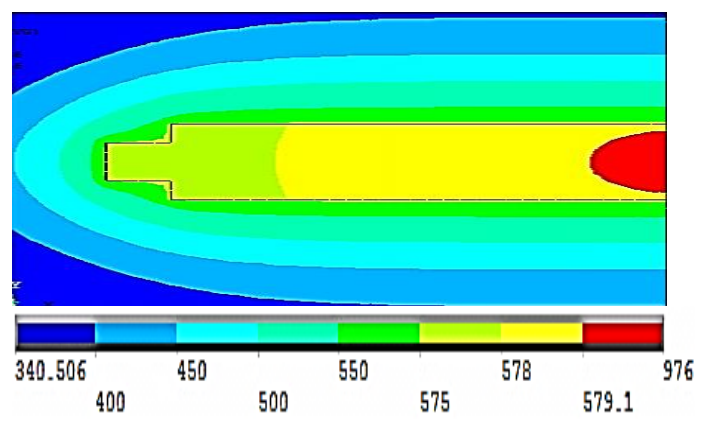

Fig. 8 (d) $t=3600$ sec, $T \max =579.146 \mathrm{~K}$

Fig. 8 (a-d) Temperature profiles at various time instances indicating maximum temperature in $\mathrm{K}$.

\section{EXPERIMENTAL VALIDATION TO DETERMINE TEMPERATURES IN CASTING}

\subsection{Calibration of Thermocouples}

Standard J-type thermocouple was used for temperature measurement. Multimeter was used as temperature recording instrument. The voltage readings from the multimeter were converted to temperature by using FLUKE thermocouple voltage to temperature calculator [17]. Calibration of thermocouple was done by testing the junction in boiling water and on ice.

\subsection{Procedure $[18,19]$}

Mould boxes of the size 450x160x80 (in $\mathrm{mm}$ ) were used as cope and drag. The conditioned sand was filled in this box and rammed. The system was so designed that the overall height of the riser was maximized to provide enough head for the riser to supply molten metal during the solidification. This could solve the problem like shrinkage in castings.

The cope and drag were placed back into position and the mould was ready to be used for casting. Initially mould was filled from top while keeping the orientation of the cavity in a horizontal manner.

But the problem like mould erosion was observed. Then, it was concluded that jet of molten metal with high rate of pouring may be a cause for mould erosion. In subsequent trial, further attempt was made with change in pouring velocity i.e. with gradual filling of the mould. But still mould erosion was not completely controlled. Later on mould was filled by orientating the parting line horizontally. Therefore the entire rigging system layout was designed and planned accordingly to ensure smooth, uniform and complete filling of the mould. To prevent entrapment of hot gases during pouring, vent holes are made by using a piercer. Few holes for insertion of thermocouples were also made by using the same process. It was ensured that the thermocouple tip had touched right at the core of the cavity. Aluminium was melted in a cast iron ladle, put in a coal fired furnace. Before pouring; it was purified by removing layers of slag on its surface. The pouring temperatures of the Aluminium alloy castings were measured by a thermocouple. Molten metal was poured and allowed to solidify and cool. The voltage readings obtained from the multimeter in $\mathrm{mV}$ as shown in Fig. 9, were converted back into temperatures based on conversion charts for standard Jtype thermocouples [17].

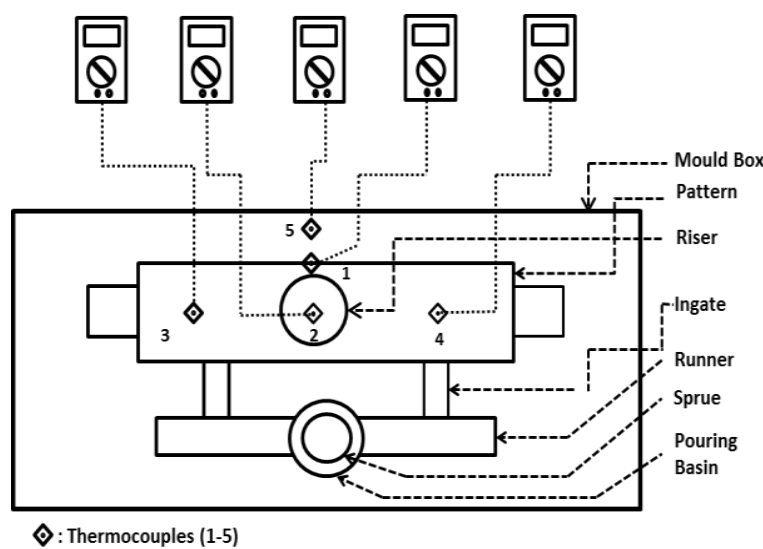

Fig. 9 Setup for Temperature Measurement with thermocouple positions 
The final casting along with the wooden pattern used, are shown in Fig. 10. The thermocouples were placed at $(225$, $130),(225,100),(225,80),(95,80)$ and $(355,80)$ from the origin (left bottom corner in $\mathrm{mm}$ ). Final casting obtained after complete solidification is shown Fig. 11. It was first cleaned with metallic brush and small burs were removed for visual inspections. Thus it was observed that the casting obtained is free from surface defects.

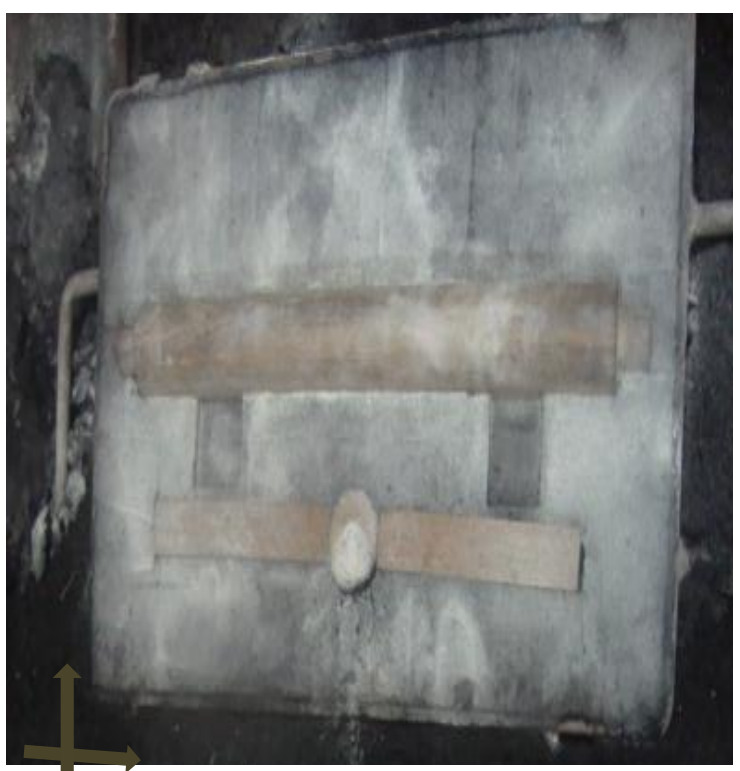

Fig. 10 Moulding box with pattern

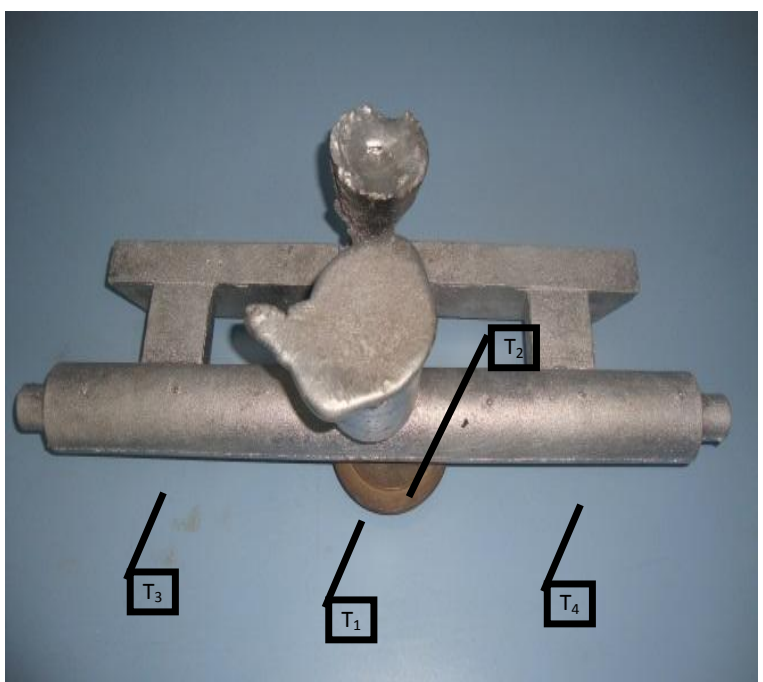

Fig.11. Final casting

\section{RESULTS}

The heat transfer during casting was studied first by available literature and then by successfully implementing a simulation in ANSYS software. The final validation was made by performing an experiment which incorporated all the parameters used for simulation environment. Temperature variation of a given node in mould area has been obtained by time-history post processing in ANSYS. Table 3 shows the temperatures for specific nodes corresponding to the actual thermocouple's location during the experimentation.

Table 3 Temperature reading at various nodes

\begin{tabular}{|l|l|l|l|l|l|}
\hline \multicolumn{2}{|l|}{} & \multicolumn{2}{l|}{$\begin{array}{l}\text { Simulation } \\
\text { Result } \\
\text { ANSYS } \\
\text { software }\end{array}$} & \multicolumn{2}{l|}{$\begin{array}{l}\text { Experimental } \\
\text { Result }\end{array}$} \\
\hline $\begin{array}{l}\text { Thermo- } \\
\text { couple } \\
\text { Location }\end{array}$ & $\begin{array}{l}\text { Coordinates } \\
\text { (mm from } \\
\text { origin) }\end{array}$ & $\begin{array}{l}\text { Max } \\
\text { Temp } \\
\text { (K) }\end{array}$ & $\begin{array}{l}\text { Min } \\
\text { Temp } \\
(\mathbf{K})\end{array}$ & $\begin{array}{l}\text { Max } \\
\text { Temp } \\
(\mathbf{K})\end{array}$ & $\begin{array}{l}\text { Min } \\
\text { Temp } \\
(\mathbf{K})\end{array}$ \\
\hline T1 & 225,100 & 880 & 470 & 883 & 473 \\
\hline T2 & 225,80 & 890 & 470 & 893 & 480 \\
\hline T3 & 95,80 & 875 & 475 & 875 & 475 \\
\hline
\end{tabular}

Note: Due to the half symmetric modeling in Ansys, T4 has not been included. Max and Min temperature recorded at $t=36 \mathrm{~s}$ and $t=3600 \mathrm{~s}$.

Temperature plots for casting region obtained by simulations (Fig. 12) and experiment (Fig. 13) prove that they are in accordance with each other after $t=900 \mathrm{sec}$. Fig. 14 shows that the temperature plots within the mould area obtained with simulation.

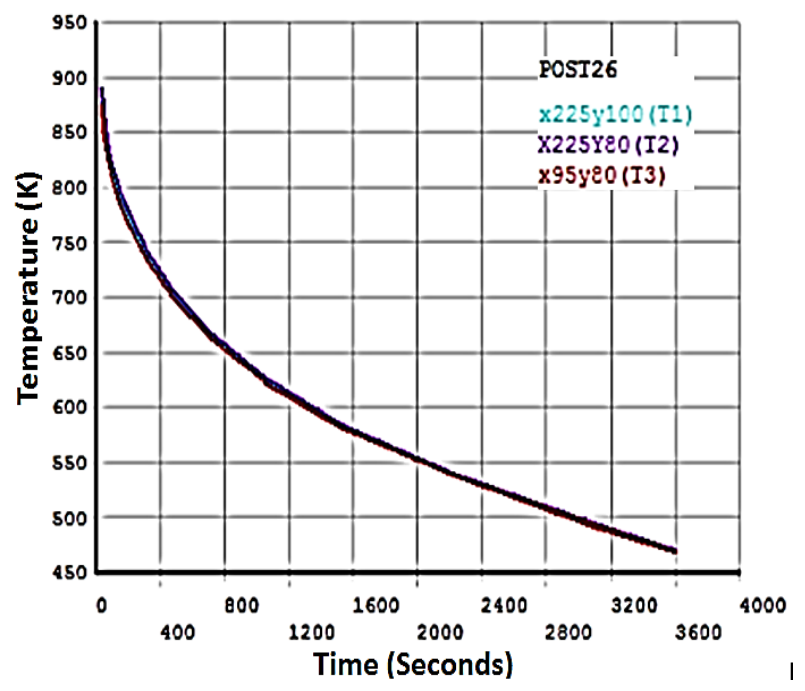

Fig.12 Temperature variation over a period of one hour obtained by ANSYS for casting region 


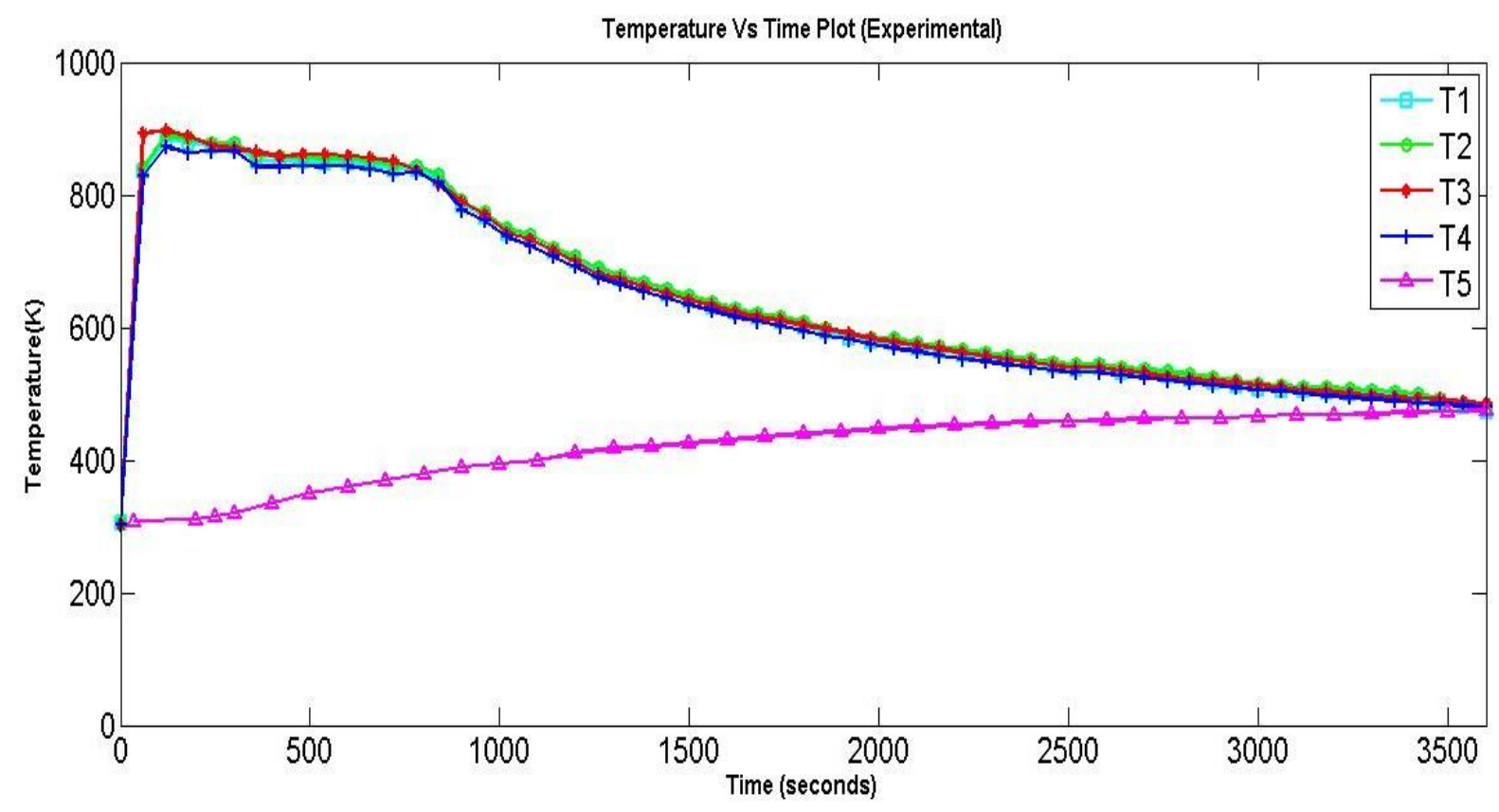

Fig.13 Temperature variation over a period of one hour obtained by experimentation

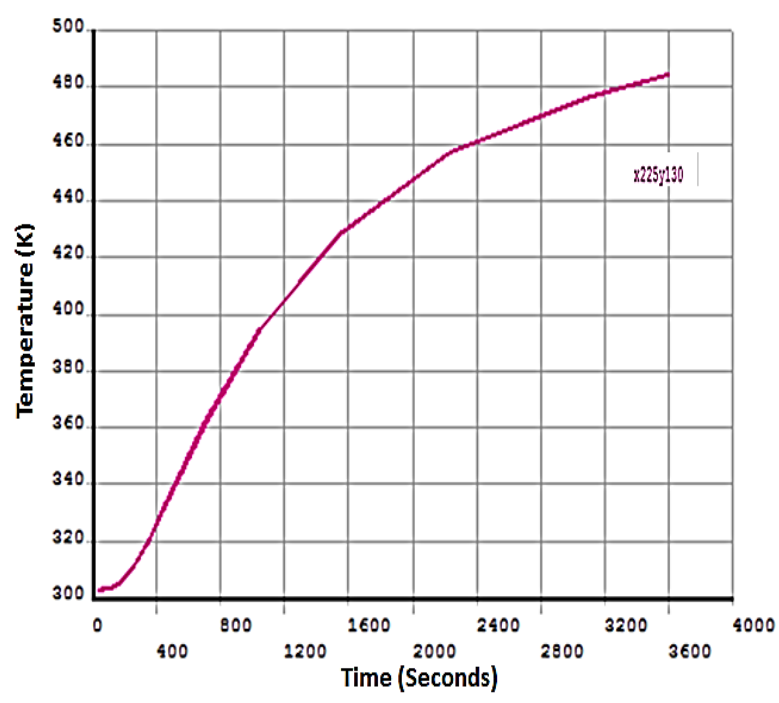

Fig.14 Temperature variation over a period of one hour obtained by ANSYS for mould region

Fig 14 shows the trend corresponding to the nodes located in sand region. Initially sand was at ambient temperature. As soon as the cavity was filled, the molten metal was started liberating the latent heat and was picked up by sand particles. It can be seen by the trend of the graph shown in Fig.14. Ansys simulation has also been performed using Thermal Solid - PLANE55 as a plane element with a 2-D thermal conduction capability. The element has four nodes with a single degree of freedom, temperature, at each node. Results obtained with triangular element are better than Thermal Solid - PLANE55 element with reference to experimental result.

\section{CONCLUSION}

Simulation of the solidification process enables visualization of the progress of freezing inside a casting and identification of the last freezing regions or hot spots. This facilitated the placement and design of feeders and feeding aids in order to maximize yield while ensuring casting soundness without expensive and time-consuming trial runs. In this paper, casting simulation using ANSYS has been carried out to obtain the isotherms at various times. These temperature variations are an important factor in improving the casting quality, reduced cost of development and speeding up the improvement of the product. Significance of the gating system at the time of filling was observed during the experimental trials. With horizontal gating system mould erosion was completely controlled as compared to the vertical one. Optimum location of riser based on software has helped in minimizing the solidification related defects, thereby providing a defect free casting (no internal cavity). The results obtained from simulations and from real casting are in good agreement which show the accuracy of model discretization in ANSYS environment. It was observed that temperature measurement with the help of thermocouple is one of the most cost effective methods as compared to temperatures data logger or virtual instruments. Thus it would prove to be a simple and economical solution for smaller foundries to get the temperature profiles.

\section{REFERENCES}

[1] C .M. Choudhari, K. J. Padalkar, K. K. Dhumal, B. E. Narkhede, S. K. Mahajan, Defect free casting by using simulation software, Applied Mechanics and Materials, 2013, 313-314, 1130-1134.

[2] Ravi B, Computer - aided Casting - Past, Present and Future, Indian Foundry J, 1999, 45, 65-74.

[3] Ravi B, Casting Method Optimization driven by Simulation, Miner Met Rev, 2008, 34(3), 39-43,

[4] T X Hou, R D Phelke and J O Wikes, Fem simulator for efficient casting solidification modelling, AFS Transaction, 1992, 100, 1057-1066.

[5] Seetharamu, K. N., Paragasam, R., Quadir, G. A., Zainal, Z. A., Prasad, B. S. A., and Sundararajan, T., Finite 
element modeling of solidification phenomena, Indian AcadSci, 2001, 26 (1\&2), 102-120.

[6] Pequet, C., Gremaud, M. and Rappaz, M., A Modeling of microprosity, macroporosity and pipe-shrinkage formation during the solidification of alloys using a mushy-zone refinement method: Applications to Aluminium alloys, Metall Mater Trans A, 2002, 33, 2095-2106.

[7] Mirbagheri, S. M. H., Dadashzadeh, M., Serajzadeh, S., Taheri, A. K., and Davami, P., Modeling the effect of mould wall roughness on the melt flow simulation in casting process, Appl Math Model, 2004, 28, 933-956.

[8] Kulkarni, S. N. and Radhakrishna, K., Prediction of solidification time of cylindrical hollow casting cast in CO2-Sand moulds by using FEA Technique, International Journal of Materials Science, 2007, 2(2), 137-152.

[9] Kermanpur, A., Mahmoudi, S. and Hajipour, A, Numerical simulation of metal flow and solidification in the multi-cavity casting moulds of automotive components, J. Mater. Process. Technol., 2008, 206, 6268.

[10] M. Masoumi, H. Hu, J. Hedjazi, M. A. Boutorabi, Effect of Gating Design on Mould Filling Paper, AFS Transactions, 2005, 05-152(2), 1-12.

[11] Hassan Iqbala, Anwar K. Sheikha, AbdulHadi AlYousefa and M. Younasa, Mould Design Optimization for Sand Casting of Complex Geometries Using Advance Simulation Tools, Mater Manuf Process, 2012, 27(7), 775-785.

[12] Vijayaram, T.R., Sulaiman, S., Hamouda, A.M.S. and Ahmad, M.H.M., Numerical simulation of casting solidification in permanent metallic moulds, J. Mater. Process. Technol., 2006, 178, 29-33.

[13] Jack P Holman, Heat Transfer, 10 edition, Mcgraw-Hill Series in Mechanical Engineering, 2009.

[14] SaeedMoaveni, Finite Element Analysis: Theory and Application with ANSYS, 3rd ed. Pearson Education, India, 2003

[15] Ansys 12.0 Tutorial, Ansys Inc., United States

[16] R.W Powell, C.Y.Ho, and P.E. Liley, Thermal conductivity of selected material, Purdue University, Indiana, November 1966

[17] FLUKE thermocouple voltage to temperature calculator: http://us.flukecal.com/Thermocoupl-TemperatureCalculator?geoip $=1$

[18] Richard W Heine, Carl R Loper and Philip C Rosenthal, 1986, Principal of Metal Casting, Tata McGraw Hill.

[19] John Campbell, Complete Casting Handbook: Metal Casting Processes, Techniques and Design, 1st ed. Butterworth-Heinemann, 2011. 